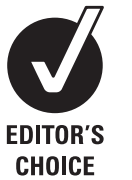

- See Commentary, p 291

${ }^{1}$ Research Centre for Prevention and Health, Glostrup University Hospital, Glostrup, Denmark ${ }^{2}$ Department of Occupational Medicine, Glostrup University Hospital, Glostrup, Denmark

\section{Correspondence to}

Dr Yrsa Andersen Hundrup, Research Centre for Prevention and Health, Glostrup University Hospital, Building 84/85, Ndr. Ringvej 57, Glostrup 2600, Denmark; yrsand01@glo. regionh.dk

Accepted 28 October 2009

\title{
Psychosocial work environment and risk of ischaemic heart disease in women: the Danish Nurse Cohort Study
}

\author{
Karen Allesøe, ${ }^{1}$ Yrsa Andersen Hundrup, ${ }^{1}$ Jane Frølund Thomsen, ${ }^{2}$ Merete Osler ${ }^{1}$
}

\section{ABSTRACT}

Objectives To investigate the effect of work pressure and job influence on the development of ischaemic heart disease (IHD) in women.

Methods The effect of work pressure and job influence on the 15-year incidence of IHD in women participating in the Danish Nurse Cohort Study was prospectively studied. A total of 12116 participants, aged 45-64 years, were examined in 1993 using a questionnaire and were followed by individual linkage in the National Register of Hospital Discharges to the beginning of 2008. Work pressure, job influence, occupational characteristics, demographic factors and known biological and behavioural risk factors for IHD were collected at baseline.

Results During follow-up, 580 participants were hospitalised with IHD. In the fully adjusted model, nurses who reported work pressure to be much too high had a 1.4-fold increased risk of incident IHD $195 \% \mathrm{Cl} 1.04$ to 1.81) compared with nurses who reported work pressure to be suitable. A tendency towards a dose-response effect was found. Age-stratified analysis showed that this effect was significant only among the younger nurses $(<51$ years old at baseline). No association was found between job influence and IHD.

Conclusions In this study we find that work pressure that is too high is a significant risk factor for $\mathrm{HD}$ in younger female employees ( $<51$ years of age). The results should be taken into account in the planning of primary prevention.

In industrialised countries, cardiovascular disease (CVD), including ischaemic heart disease (IHD), is the leading cause of death and affects as many women as men. ${ }^{1}$ In Denmark, more than one third of all deaths among women are caused by CVD. ${ }^{2}$ Many risk factors are similar for men and women, but gender differences are known to exist. ${ }^{3}$

During the last decades, several studies have examined the impact of work-related psychosocial factors on IHD. A review from 2000 of cohort and case-control studies of men concluded that a combination of excessive psychological demands and lack of control (job strain) increases the risk of IHD. ${ }^{4}$ More recent reviews have found the evidence inconclusive ${ }^{56}$ and in some of these the effect of job strain can be fully explained by the association between demands and risk of IHD. ${ }^{6}$ A meta-analysis from 2006 also showed a heterogeneous picture of the association between work related stress and the risk of IHD, and it is suggested that work stress is a less powerful predictor of IHD in women; however, only a few studies on women are available.
In highly industrialised countries in general and in Denmark in particular, the employment rates of men and women are very similar. ${ }^{8}$ Indeed, a Danish study in 1991 found that almost twice as many women as men were employed in jobs characterised by high job demands and a low degree of control, ${ }^{9}$ which in some studies have been found to have adverse health effects. Thus, many employed women are exposed to potentially hazardous factors at work.

The evidence linking adverse psychosocial work factors to IHD in women is still inconclusive. The effect of high demands has shown a significant association with increased risk of IHD in some studies, ${ }^{10} 11$ and no effect in others. ${ }^{12-15}$ The impact of lack of control or one of the dimensions of job control (decision authority and skill discretion) on IHD in women has shown a significant association in some studies ${ }^{12}{ }^{15}$ and no effect in others. ${ }^{14} 16$ Studies not separating gender in the analyses have demonstrated an effect of control but not of demands. ${ }^{17} 18$

The large group of women covered by the Danish Nurse Cohort Study allows the use of a prospective design to establish the temporal sequence between exposure and IHD. In addition, survey data are combined with register data on incident IHD.

Based on this cohort the purpose of the present study was to investigate the effect of work pressure and job influence on the development of IHD in women.

\section{METHODS}

\section{Study population and exclusion criteria}

The Danish Nurse Cohort Study was established in 1993 when all Danish nurses aged 45 years and over and members of the Danish Nurses' Association $(n=23170)$ received a comprehensive self-administered questionnaire on health and lifestyle, including occupational status and working conditions. Practically all nurses in Denmark are members of the Danish Nurses' Association, and the coverage of female nurses is nearly 100\%. Overall, 19898 women $(86 \%)$ returned the questionnaire. ${ }^{19}$ Women who at baseline were not actively employed as nurses ( $n=7501)$ or who had passed retirement age, which in Denmark is 65 years, $(n=86)$ were excluded. Based on register information, we excluded 105 women with a hospital admission for IHD prior to the baseline survey and two women who completed the questionnaire but who were registered in The Central Person Registry as missing or having emigrated. Furthermore, women with missing information on psychosocial work 
environment were excluded ( $\mathrm{n}=88)$. Thus, the study population consisted of was 12116 women.

\section{Measures of psychosocial working conditions}

One item dealt with work pressure and another item with one of the aspects of work control, that is job influence. Each of the items was analysed separately and categorised as follows:

1. What is the work pressure/work speed at your work: Much too low/a little too low, suitable, a little too high, much too high?

2. Normally, how great is your influence on the organisation of your daily work: Major influence, a certain influence, minor/ no influence?

\section{Covariates}

Information on the following covariates was all self-reported and collected at baseline through the questionnaire. The included covariates were: age, marital status, number of children, nature of the work, working hours, shift working, physical activity at work, family history of cardiac disease, diabetes, menopausal status, body mass index (BMI; calculated as weight in kilograms divided by square of height in metres), smoking history, alcohol intake and leisure time physical activity.

\section{Endpoints}

Subjects were censored when a first ever hospitalisation for IHD occurred (cases) or when they died, emigrated or disappeared. Information on hospitalisation for a first ever IHD event was retrieved from the Danish National Patient Registry, which through a personal identification number registers all hospital admissions in Denmark. Information on dates of death, emigration or disappearance was obtained from the Central Person Registry.

The National Patient Registry of Hospital Discharges is based on International Classification of Diseases coding. IHD cases were defined as first ever myocardial infarction (410 in ICD-8 and I21-23 in ICD-10), other acute or chronic IHD (411-412 in ICD-8 and I24-25 in ICD-10), angina (413 in ICD-8 and I20 in ICD-10) or electrocardiographically diagnosed heart disease (414 in ICD-8). Follow-up for events was continued until 5 February 2008.

\section{Statistical methods}

Cox proportional hazards models were used to test for association between IHD and the psychosocial working conditions and covariates. In these analyses we adjusted for age, categorised in 5 -year groups, and 95\% CI was calculated.

In a first Cox model we adjusted for age in 5-year groups and a fixed set of covariates: family history of IHD, diabetes, menopausal status, BMI, smoking, alcohol and leisure time physical activity (model B). All other covariates were tested in bivariate analyses for association with IHD and those which were significant (shift work and physical activity at work) were included in model $\mathrm{C}$ along with age and the fixed set of confounders. As sensitivity analyses, we used the same Cox models to analyse the association between work pressure and all IHD diagnoses except angina pectoris and angina pectoris alone, respectively.

In a separate Cox model we analysed the effect of age. We dichotomised age by the median value. Statistical interaction between this variable and work pressure was analysed by including a term of interaction in the model.

In the Cox models the proportional hazards assumption was evaluated for all variables by comparing estimated log-log survivor curves over the different categories of variables being investigated and by inspecting plots of Schoenfeld residuals.

Statistical analyses were performed using the statistical package SAS v 9.2 .

\section{RESULTS}

The study included 12116 women who in 1993 were actively employed. Their median age was 51 years. During the 15 years of follow-up, a total of 580 incident cases of IHD occurred. Among the 580 incident cases, 369 were angina pectoris, 138 were myocardial infarction and 73 other IHD.

In table 1 , the basic model (A) shows that nurses who reported work pressure to be much too high compared to those reporting a suitable work pressure had a nearly $50 \%$ increased risk of developing IHD (hazard ratio (HR) 1.47 (95\% CI 1.14 to 1.88)). Furthermore, nurses who reported work pressure to be a little too high had an approximately 25\% increased risk (HR 1.25 (95\% CI 1.04 to 1.50$)$ ). It should be noted that about $60 \%$ of the nurses reported work pressure to be much too high or a little too high. No significant increased risk of IHD was found in nurses who reported having minor or no influence on the organisation of their daily work (table 1, model A).

The association between work pressure that was much too high and IHD remained significant but was reduced after inclusion of traditional cardiovascular risk factors (HR 1.35 (95\% CI 1.03 to 1.76)) (table 1 , model B).

Inclusion of the covariates "shift work" and "physical activity at work" in model B had only a minor influence on the effect on the risk of IHD of having work pressure that was too high compared to model B (HR 1.38 (95\% CI 1.04 to 1.81)) (table 1, model C).

Stratifying by the median value of age at baseline ( 51 years) showed that the association between work pressure and IHD was strongest and only significant among the younger nurses (table 2).

In a sub-analysis work pressure that was much too high was also a significant predictor of IHD when we omitted the angina pectoris diagnoses as events, both in the age adjusted analyses (HR 1.69 (95\% CI 1.15 to 2.49)) and when controlling for traditional cardiovascular risk factors, shift work and physical activity at work (HR 1.70 (95\% CI 1.10 to 2.62)). No association between work pressure that was much too high and angina pectoris was found either in the age adjusted analyses (HR 1.33 (95\% CI 0.96 to 1.84)) or when controlling for traditional cardiovascular risk factors, shift work and physical activity at work (HR 1.25 (95\% CI 0.88 to 1.78)).

In separate analyses we have studied the effect of work pressure on the risk of IHD in the same study population but with a 5-year follow-up (1993-1998). With a 5-year follow-up the hazard ratios for IHD associated with work pressure that was too high were: work pressure that was a little too high: HR 1.60 (95\% CI 1.12 to 2.27 ) and work pressure that was much too high: HR 1.97 (95\% CI 1.25 to 4.00) (adjusted for traditional risk factors for IHD, shift work and physical activity at work).

\section{DISCUSSION}

This cohort study of a large sample of female nurses at work showed that self-reported work pressure that was too high was a predictor of IHD. A tendency towards a dose-response in the effect was found as nurses who reported work pressure to be much too high had an age adjusted 50\% elevated risk of developing IHD compared to nurses who reported the work pressure to be suitable, whereas nurses who reported the work pressure to 
Table 1 The effect of including covariates on hazard ratios for ischaemic heart disease according to work pressure among nurses participating in the Danish Nurse Cohort Study, 1993-2008

\begin{tabular}{|c|c|c|c|c|c|c|}
\hline \multirow[b]{2}{*}{ Characteristics } & \multicolumn{2}{|c|}{ Basic model $A^{*}, \S$} & \multicolumn{2}{|c|}{ Model B十,§ } & \multicolumn{2}{|c|}{ Model C $\ddagger$ § } \\
\hline & HR & $95 \% \mathrm{CI}$ & $\overline{\mathrm{HR}}$ & $95 \% \mathrm{Cl}$ & $\overline{\mathrm{HR}}$ & $95 \% \mathrm{CI}$ \\
\hline \multicolumn{7}{|l|}{ Work pressure } \\
\hline Much/a little too low & 1.44 & 0.64 to 3.25 & 1.51 & 0.66 to 3.42 & 1.45 & 0.63 to 3.29 \\
\hline Suitable & 1 & & 1 & & 1 & \\
\hline A little too high & 1.25 & 1.04 to 1.50 & 1.24 & 1.02 to 1.50 & 1.26 & 1.03 to 1.53 \\
\hline Much too high & 1.47 & 1.14 to 1.88 & 1.35 & 1.03 to 1.76 & 1.38 & 1.04 to 1.81 \\
\hline \multicolumn{7}{|l|}{ Job influence } \\
\hline Major influence & 1 & & & & & \\
\hline Some influence & 1.02 & 0.86 to 1.22 & & & & \\
\hline Minor or no influence & 1.01 & 0.76 to 1.34 & & & & \\
\hline \multicolumn{7}{|l|}{ Family history of IHD } \\
\hline No & 1 & & 1 & & 1 & \\
\hline Yes & 2.12 & 1.62 to 2.78 & 2.01 & 1.50 to 2.70 & 2.01 & 1.49 to 2.68 \\
\hline Not known & 1.44 & 1.13 to 1.84 & 1.36 & 1.05 to 1.76 & 1.34 & 1.03 to 1.72 \\
\hline \multicolumn{7}{|l|}{ Diabetes } \\
\hline No & 1 & & 1 & & 1 & \\
\hline Yes & 4.65 & 2.97 to 7.27 & 4.31 & 2.67 to 6.94 & 4.30 & 2.67 to 6.93 \\
\hline \multicolumn{7}{|l|}{ Menopausal status } \\
\hline Pre-menopausal & 1 & & 1 & & 1 & \\
\hline Postmenopausal & 1.41 & 1.10 to 1.80 & 1.22 & 0.94 to 1.58 & 1.21 & 0.94 to 1.58 \\
\hline \multicolumn{7}{|l|}{ BMI } \\
\hline$<25$ & 1 & & 1 & & 1 & \\
\hline $25 \leq \mathrm{BMI}<30$ & 1.21 & 1,00 to 1.47 & 1.20 & 0.98 to 1.48 & 1.19 & 0.96 to 1.45 \\
\hline$\geq 30$ & 1.75 & 1.29 to 2.37 & 1.71 & 1.24 to 2.35 & 1.69 & 1.23 to 2.33 \\
\hline \multicolumn{7}{|l|}{ Smoker } \\
\hline Never/former & 1 & & 1 & & 1 & \\
\hline Current & 1.50 & 1.27 to 1.78 & 1.57 & 1.31 to 1.87 & 1.55 & 1.30 to 1.84 \\
\hline \multicolumn{7}{|l|}{ Alcohol intake } \\
\hline No intake & 1.33 & 1.06 to 1.65 & 1.30 & 1.03 to 1.63 & 1.25 & 0.99 to 1.57 \\
\hline $1-28$ units/week & 1 & & 1 & & 1 & \\
\hline$>28$ units/week & 1.25 & 0.98 to 1.60 & 1.19 & 0.92 to 1.54 & 1.20 & 0.93 to 1.55 \\
\hline \multicolumn{7}{|l|}{ Leisure time physical activity } \\
\hline$>4$ h/week hard & 1 & & 1 & & 1 & \\
\hline$\leq 4 \mathrm{~h} /$ week moderate & 1.10 & 0.91 to 1.38 & 1.16 & 0.94 to 1.43 & 1.19 & 0.96 to 1.45 \\
\hline Sedentary & 1.63 & 1.16 to 2.28 & 1.47 & 1.02 to 2.12 & 1.52 & 1.05 to 2.18 \\
\hline \multicolumn{7}{|l|}{ Shift work } \\
\hline Day & 1 & & & & 1 & \\
\hline Evening & 1.05 & 0.82 to 1.35 & & & 0.94 & 0.71 to 1.24 \\
\hline Night & 1.44 & 1.11 to 1.87 & & & 1.19 & 0.86 to 1.63 \\
\hline Rotate & 0.91 & 0.72 to 1.15 & & & 0.81 & 0.63 to 1.04 \\
\hline \multicolumn{7}{|l|}{ Physical activity at work } \\
\hline Sedentary/not physically exerting & 1 & & & & 1 & \\
\hline Physically exerting/strenuous & 1.36 & 1.15 to 1.61 & & & 1.28 & 1.05 to 1.54 \\
\hline
\end{tabular}

$\mathrm{BMI}$, body mass index; HR, hazard ratio; IHD, ischemic heart disease.

*Adjusted for age.

†Adjusted for age and risk factors for IHD (family history of IHD, diabetes, menopausal status, BMI, smoking, alcohol consumption, leisure time physical activity).

$\ddagger$ Adjusted for age, risk factors for IHD, shift work and physical activity at work.

$\S$ The type 3 test for work pressure in the Cox models was: $p=0.012$ in model $A, p=0.066$ in model $B$ and $p=0.059$ in model $C$.

Table 2 Study population stratified by median age: hazard ratio and $95 \% \mathrm{Cl}$ for ischemic heart disease by level of work pressure*

\begin{tabular}{lllll}
\hline & & \multicolumn{2}{l}{ Work pressure } \\
\cline { 3 - 5 } Age & $\begin{array}{l}\text { Number } \\
\text { of cases }\end{array}$ & Suitable & $\begin{array}{l}\text { A little too high } \\
\text { HR (95\% CI) }\end{array}$ & $\begin{array}{l}\text { Much too high } \\
\text { HR (95\% CI) }\end{array}$ \\
\hline$<51$ & 176 & 1 & $1.57(1.09$ to 2.25$)$ & $1.94(1.25$ to 3.01$)$ \\
$\geq 51$ & 345 & 1 & $1.09(0.77$ to 1.55$)$ & 0.97 (0.69 to 1.35)
\end{tabular}

BMI, body mass index; HR, hazard ratio; IHD, ischemic heart disease.

*Adjusted for age in two groups for traditional risk factors for IHD: Family history of IHD diabetes, menopausal status, BMI, smoking, alcohol, and leisure time physical activity as well as shift work and physical activity in work. We found no statistical interaction between work pressure and age $(p=0.1968)$. be a little too high had a smaller but still significant increased risk of developing IHD. The estimates had narrow confidence intervals and the effects remained significant after adjustment for biological and behavioural risk factors for IHD, shift work and physical activity at work. It is noteworthy that the association between high work pressure and IHD was only significant among the younger nurses.

Furthermore, having work pressure that was much too high was a significant predictor of IHD even when angina pectoris was excluded both in age adjusted analyses and when controlling for traditional cardiovascular risk factors, shift work and physical activity at work. No evidence was found of a relationship between having influence on the organisation of daily work (job control) and the risk of IHD. 
A general problem in this field of research is the use of different measures of psychosocial work exposures. ${ }^{6}$ Our study measures only one aspect of job demands, namely work pressure. This may limit the comparison of our results with previous studies. In spite of these limitations, we think that recent studies demonstrating an effect of psychosocial demands provide some support for our findings.

A European prospective multi-centre study from 2006 by Kornitzer et $\mathrm{al}^{20}$ found that men exposed to high psychosocial job demands had a nearly $50 \%$ increased risk of developing a coronary event. A contemporary Danish cohort study of men found a consistent association between psychological job demands and the risk of IHD, ${ }^{21}$ and in the Whitehall II Study high job demands increased the risk of coronary heart disease events in both men and women. ${ }^{11}$

In the American Nurses' Health Study, Lee et al ${ }^{13}$ could not demonstrate that either high job demands or low job control was associated with IHD, but this may be due to selection bias, as pointed out by Kivimäki et al, ${ }^{7}$ or cultural differences as pointed out by Eller et al. ${ }^{6}$ The Framingham Offspring Study ${ }^{12}$ found no effect of high job demands on heart disease among women, but this study included elderly participants up to 77 years of age and had a 10-year follow-up which may have diluted the effects. Another possible explanation could be that the study was based on self-reported exposure in a broad population. Different occupational groups may experience job demands differently, ${ }^{22}$ and this could lead to misclassification and a dilution of effects. For this reason self-reported job demands might be difficult to measure across occupational groups as has been pointed out by others. ${ }^{17} 23$ This might also be one explanation for the lack of effect of job demands in a Swedish study by Kuper et al. ${ }^{14}$

Evidence of an association between job demands and IHD has not been demonstrated in studies using a job exposure matrix. ${ }^{1724}$ This may be due to a considerable degree of misclassification associated with this method. Netterstrøm used both self-reported and matrix data but found only an effect of job demands based on the self-reported data. If the perception of demands is a more individual matter than the perception of control, this might explain why the effect of low control is more often seen in studies using aggregated data and the effect of high demands is not. 6

In the present study the age-stratified analysis showed a stronger and significant association between work pressure that was too high and IHD only in the younger nurses. Even though we were unable to demonstrate a significant age interaction, it seems as if the effect of work pressure has a greater impact on younger nurses. This is in agreement with findings from previous studies looking at age-specific effects in both men and women. ${ }^{112526}$ The lower risk among the older nurses may be due to other risk factors that become relatively more important with increasing age. Futhermore vulnerable individuals may have left work. Another explanation might be that the oldest cohort members have retired and are no longer exposed to work related stress factors. These findings are in accordance with a recent study demonstrating that inclusion of employees older than 55 years of age in a cohort diluted the effect of job strain on ischaemic disease ${ }^{27}$; this is especially a problem if such studies are combined with a long follow-up.

In our study we have a rather long follow-up time and as the exposure was only measured at baseline, this may have diluted the effects. In the separate analyses of the effect of work pressure on the risk of IHD with a 5-year follow-up (1993-1998), we found a stronger effect of high work pressure on the risk of IHD in the analyses with the short follow-up compared to the anal- yses with the long follow-up (15 years). More studies are needed to determine the extent to which duration and continuity of exposure may influence the size of the risk and whether the harm caused by work related stress is irreversible or attenuated as time passes since the exposure ceased. It is also important to study the mechanisms by which work related factors might lead to IHD, for example, whether the exposure causes atherosclerosis or whether it triggers IHD in individuals who already have atherosclerosis.

The present study could not confirm that low job control is associated with an increased risk of IHD. This could be due to the fact that the only question concerning job control has a narrower meaning than the question concerning work pressure. Furthermore, the question only relates to one of the two dimensions of job control, that is decision authority. We have no information concerning the other dimension, which is skill discretion. A recent Danish study showed that this dimension in part mediated the effect of socioeconomic position on the risk of myocardial infarction, while no effect of decision authority was found. ${ }^{17}$ Another Danish study found a non-significant relative risk of IHD among men having little control in the planning of their working conditions. ${ }^{21}$ Kornitzer et $a l^{20}$ found no effect of low job control on the risk of a coronary event.

\section{Strengths and weaknesses of the study}

A strength of this study is that it examines a cohort of women with sufficient statistical power given the size of the cohort and the number of cases found during follow-up. Other strengths are the high response rates obtained in this cohort of Danish nurses, the validity of the self-reported information provided by the nurses $^{28-30}$ and the fact that the study is based on the entire population of Danish nurses. Furthermore, information on IHD was obtained through individual linkage to a nationwide hospital register. This linkage also made it possible to exclude women with a hospital admission for IHD before the baseline survey. The follow-up is nearly complete apart from some patients with less harmful heart disease such as angina pectoris who are treated in general practice and are not registered in the Danish National Patient Registry. This might have caused a small degree of nondifferential misclassification, and if so the effect may tend to be underestimated. However, if personality factors were related both to the likelihood of reporting work pressure that was too high and to a greater chance of being hospitalised with angina pectoris, then this could have led to serious misclassification. ${ }^{31}$ In this case it strengthens our result that high work pressure increased the risk of myocardial infarction and other types of IHD apart from angina pectoris, diagnoses not solely based on symptoms and which normally require objective diagnostic measurements.

The combination of a rather long follow-up and that fact that some of the cohort members were close to normal retirement age at baseline means that an increasing number of cohort members were no longer exposed to work factors. This may have caused some misclassification and reduced the strength of the association.

\section{Confounding}

Confounding due to gender, education and especially socioeconomic status is avoided due to the homogeneous population. Job control is known to be a strong surrogate marker of social class which may otherwise be a problem in cohorts of broad populations. Furthermore, since the cohort of Danish nurses was established specifically to study risk factors for atherosclerosis, a broad spectrum of risk factors for IHD was available. However, 
residual confounding from unmeasured factors might still be a problem. As for the psychosocial work factors, the covariates were also measured at one point in time only, which may lead to some degree of misclassification and underestimation of the effect of the covariates.

\section{Measures of psychosocial working conditions}

In the present study exposure status is measured only by two questions, which means that important aspects, especially of the control dimension, may have been overlooked. This also makes comparison with other studies difficult and furthermore the psychosocial working conditions are measured with less accuracy. Work pressure is measured on the basis of a single question with a somewhat complex and global meaning since it relates to both tempo and work pressure at the work place. Furthermore, it asks specifically if the work pressure is too high, indicating that most of those who choose this answer, find it a nonpreferred condition. It is important further to investigate factors that contribute to the perception that work pressure is too high, as it may include different aspects of work demands as well as aspects of not being able to control the work load.

\section{CONCLUSIONS}

Our study shows that work pressure that was self-reported as being too high significantly increases the risk of IHD in younger female nurses ( $<51$ years). The association between work pressure that was much too high and IHD was also found when angina pectoris was excluded. None of these associations could be explained by traditional coronary risk factors.

This study adds to the previous body of evidence suggesting harmful effects of excessive psychological demands at work on cardiac health, but is one among very few that demonstrates the effect among women. The results should be taken into account in primary prevention. Additional work should be carried out to identify factors contributing to the perceived high work pressure.

Acknowledgements The original data for this study were collected and provided by the Danish Nurse Cohort Study, Research Centre for Prevention and Health, Glostrup University Hospital, Denmark.

\section{Competing interests None.}

Ethics approval The Danish Ethics Committee for the City of Copenhagen and Frederiksberg approved the study (\# 11-035/00).

Provenance and peer review Not commissioned; externally peer reviewed.

\section{REFERENCES}

1. Stramba-Badiale M, Fox KM, Priori SG, et al. Cardiovascular diseases in women a statement from the policy conference of the European Society of Cardiology. Eur Heart J 2006;27:994-1005.

2. Madsen M, Kjøller M, Rasmussen S. Kvinder og hjertesundhed - en rapport om sundhedsadfærd og hjertesygdom hos kvinder Copenhagen: Statens Institut for Folkesundhed [National Institute for Public Health], 2003.

3. Bittner V. Women and coronary heart disease risk factors. J Cardiovasc Risk 2002;9:315-22.

4. Steenland K, Fine L, Belkic K, et al. Research findings linking workplace factors to CVD outcomes. Occup Med 2000;15:7-68.
5. Kuper H, Marmot M, Hemmningway H. Systematic review of prospective cohort studies of psychosocial factors in the etiology and prognosis of coronary heart disease. Semin Vasc Med 2002;2:267-314.

6. Eller NH, Netterstrøm B, Gyntelberg F, et al. Work-related psychosocial factors and the development of ischemic heart disease. A systematic review. Cardiol Rev 2009;17:83-97.

7. Kivimäki M, Virtanen M, Elovainio M, et al. Work stress in the etiology of coronary heart disease - a metaanalysis. Scand J Work Environ Health 2006;32:431-42.

8. Videbæk J, Madsen M. Hjertestatistik [Heart statistics]. Copenhagen: The Danish Heart Foundation and the National Institute of Public Health, 2004.

9. Netterstrom B, Kristensen TS, Damsgaard MT, et al. Job strain and cardiovascular risk factors: a cross sectional study of employed Danish men and women. $\mathrm{Br} \mathrm{J}$ Ind Med 1991;48:684-9

10. Alfredsson L, Spetz C-L, Theorell T. Type of occupational and near-future hospitalization for myocardial infarction and some other diagnoses. Int J Epidemiol 1985; 14:378-88

11. Kuper H, Marmot M. Job strain, job demands, decision latitude, and risk of coronary heart disease within the Whitehall II Study. J Epidemiol Community Health 2003; 57:147-53

12. Eaker ED, Sullivan LM, Kelly-Hayes M, et al. Does job strain increase the risk for coronary heart disease in men and women? Am J Epidemiol 2004;159:950-8.

13. Lee $\mathbf{S}$, Colditz $\mathrm{G}$, Berkman L, et al. A prospective study of job strain and coronary heart disease in US women. Int J Epidemiol 2002;31:1147-53.

14. Kuper H, Adami H-O, Theorell T, et al. Psychosocial determinants of coronary heart disease in middle-aged women: a prospective study from Sweden. Am J Epidemiol 2006;164:349-57.

15. Hammar N, Alfredsson L, Johnson JV. Job strain, social support at work, and incidence of myocardial infarction. Occup Environ Med 1998:55:548-53.

16. Lee S, Colditz G, Berkman LF, et al. A prospective study of job insecurity and coronary heart disease in US women. Ann Epidemiol 2004;14:24-30.

17. Andersen I, Burr H, Kristensen TS, et al. Do factors in the psychosocial work environment mediate the effect of socioeconomic position on the risk of myocardial infarction? Study from the Copenhagen Centre for Prospective Population Studies. Occup Environ Med 2004:61:886-92.

18. Bonde JP, Munch-Hansen T, Agerbo E, et al. Job strain and ischemic heart disease: a prospective study using a new approach for exposure assessment. J Occup Environ Med 2009;51:732-8.

19. Hundrup YA, Thoning $\mathrm{H}$, Obel EB, et al. Life-style factors and choice of hormone replacement therapy among Danish nurses. Scand J Public Health 2002:30:47-53.

20. Kornitzer $\mathbf{M}$, deSmet $P$, Sans $\mathbf{S}$, et al. Job stress and major coronary events: results from the Job Stress, Absenteeism and Coronary Heart Disease in Europe study. Eur J Cardiovasc Prev Rehabil 2006;13:695-704.

21. Netterstrøm B, Kristensen TS, Sjøl A. Psychological job demands increase the risk of ischaemic heart disease: a 14-year cohort study of employed Danish men. Eur $J$ Cardiovasc Prev Rehabil 2006;13:414-20.

22. KasI SV. Measuring job stressors and studying the health impact of work environment: an epidemiological commentary. J Occup Health Psychol 1998; 3:390-401

23. Levi L, Baertley M, Marmot M, et al. Stressors at the work place: theoretical models Occup Med 2000:15:69-106.

24. Hall EM, Johnson JV, Tsou TS. Women, occupation, and risk of cardiovascular morbidity and mortality. Occup Med 1993;8:709-19.

25. Hammar H, Carlson F. Smokers' decisions to quit smoking Gothenburg: Gothenburg University, Department of Economics, 2001:1-23.

26. Theorell T, Karasek R. Current issues relating to psychosocial job strain and cardiovascular disease research. J Occup Health Psychol 1996:1:9-26.

27. Kivimäki M, Theorell T, Westerlund $\mathrm{H}$, et al. Job strain and ischaemic disease: does the inclusion of older employees in the cohort dilute the association? The WOLF Stockholm Study. J Epidemiol Community Health 2008;62:372-4.

28. Colditz GA, Martin P, Stampfer MJ, et al. Validation of questionnaire information on risk factors and disease outcomes in a prospective cohort study of women. Am J Epidemiol 1986;123:894-900.

29. Hundrup YA, Høidrup S, Obel EB, et al. Validity of self-reported fractures among Danish nurses compared to fractures in the Danish National Hospital Register. Scand $J$ Public Health 2004;32:136-43.

30. Løkkegaard $\mathbf{E}$, Johnsen SP, Heitmann BL, et al. The validity of self-reported use of hormone replacement therapy among Danish nurses. Acta Obstet Gynecol Scand 2004;83:476-81

31. Macleod J, Smith GD, Heslop P, et al. Psychological stress and cardiovascular disease: empirical demonstration of bias in a prospective observational study of Scottish men. BMJ 2002;324:1247-51. 